\title{
Happiness and loss aversion: when social participation dominates comparison
}

Citation for published version (APA):

Vendrik, M. C. M., \& Woltjer, G. B. (2006). Happiness and loss aversion: when social participation dominates comparison. METEOR, Maastricht University School of Business and Economics. METEOR Research Memorandum No. 027 https://doi.org/10.26481/umamet.2006027

Document status and date:

Published: 01/01/2006

DOI:

10.26481/umamet.2006027

Document Version:

Publisher's PDF, also known as Version of record

\section{Please check the document version of this publication:}

- A submitted manuscript is the version of the article upon submission and before peer-review. There can be important differences between the submitted version and the official published version of record. People interested in the research are advised to contact the author for the final version of the publication, or visit the DOI to the publisher's website.

- The final author version and the galley proof are versions of the publication after peer review.

- The final published version features the final layout of the paper including the volume, issue and page numbers.

Link to publication

\footnotetext{
General rights rights.

- You may freely distribute the URL identifying the publication in the public portal. please follow below link for the End User Agreement:

www.umlib.nl/taverne-license

Take down policy

If you believe that this document breaches copyright please contact us at:

repository@maastrichtuniversity.nl

providing details and we will investigate your claim.
}

Copyright and moral rights for the publications made accessible in the public portal are retained by the authors and/or other copyright owners and it is a condition of accessing publications that users recognise and abide by the legal requirements associated with these

- Users may download and print one copy of any publication from the public portal for the purpose of private study or research.

- You may not further distribute the material or use it for any profit-making activity or commercial gain

If the publication is distributed under the terms of Article $25 \mathrm{fa}$ of the Dutch Copyright Act, indicated by the "Taverne" license above, 
Maarten Vendrik, Geert Woltjer

Happiness and Loss Aversion: When Social

Participation Dominates Comparison

$\mathrm{RM} / 06 / 027$

JEL code: I31, D6

\section{METE@R}

Maastricht research school of Economics of TEchnology and ORganizations

Universiteit Maastricht

Faculty of Economics and Business Administration P.O. Box 616

NL - 6200 MD Maastricht

phone : ++31433883830

fax $\quad$ :+31433884873 



\title{
Happiness and Loss Aversion: \\ When Social Participation Dominates Comparison
}

\author{
Maarten Vendrik \\ Geert Woltjer ${ }^{1}$
}

\begin{abstract}
A central finding in happiness research is that a person's income relative to the average income in her social reference group is more important for her life satisfaction than the absolute level of her income. This dependence of life satisfaction on relative income can be related to the reference dependence of the value function in Kahneman and Tversky's (1979) prospect theory. In this paper we investigate whether the characteristics of the value function like concavity for gains, convexity for losses, and loss aversion apply to the dependence of life satisfaction on relative income. This is tested with a new measure for the reference income for a large German panel for the years 1984-2001. We find concavity of life satisfaction in positive relative income, but unexpectedly strongly significant concavity of life satisfaction in negative relative income as well. The latter result is shown to be robust to extreme distortions of the reported-life-satisfaction scale. It implies a rising marginal sensitivity of life satisfaction to more negative values of relative income, and hence loss aversion (in a wide sense). This may be explained in terms of increasing financial obstacles to social participation.
\end{abstract}

JEL codes: I31, D6

Keywords: life satisfaction, relative income, value function, loss aversion, social participation

\footnotetext{
${ }^{1}$ Both authors, Department of Economics, Maastricht University, P.O. Box 616, 6200 MD Maastricht, The Netherlands, E-mail corresponding author: M.Vendrik@algec.unimaas.nl. Tel. 0031-43-3883638(3883636). Fax: 0031-43-3884878.

We thank Johannes Abeler, Andrew Clark, David Huffman, Winfried Koeniger, Ben Kriechel, Felix Marklein, Joan Muysken, Erik de Regt, Alois Stutzer, Bob Sugden, Uwe Sunde, Peter Wakker, and other participants to the $2^{\text {nd }}$ Workshop on "Capabilities and Happiness" in Milano-Bicocca, June, 2005, and seminars in Maastricht and Bonn (IZA) for helpful comments on earlier versions of this paper. We are also indebted to Denis de Crombrugghe and Sybrand Schim van der Loeff for econometric advice.
} 


\section{Introduction}

A basic postulate of utility theory is that utility rises with income. However, empirical research on subjective well-being (see Frey and Stutzer, 2002a, for an overview) has shown that in most developed countries average happiness has not or only slightly increased over the last fifty years despite high economic growth. This paradox has been explained by Easterlin $(1974,2001)$ and Frank (1997) in terms of rising aspirations and social comparison. The level of one's income relative to that of other people is more important than its absolute level, and if absolute income rises for everybody at the same pace, relative income does not change. This importance of relative income was found earlier by Duesenberry (1949) in his seminal study on individual consumption and savings behaviour. In addition, Duesenberry postulated that social comparisons of income are not symmetric. In the context of happiness this means that the happiness of poorer people is negatively affected by the income of their richer peers, whereas richer people do not become happier from comparing their income with that of poorer members of their reference group.

Thirty years later, Kahneman and Tversky (1979) introduced their prospect theory as an alternative to the standard microeconomic theory of choice. It includes a value function that is defined over gains and losses with respect to some natural reference point and that is concave for gains and convex for losses. It is also assumed to be steeper for losses than for gains, which is referred to as loss aversion (Tversky and Kahneman, 1991). Finally, the value function is hypothesized to be as convex for losses as it is concave for gains (reflection effect, Kahneman (2003); see Köbberling et al. (2004) for a different hypothesis).

These characteristics of the value function have been tested extensively for decision utility and psychological perceptions (see Köbberling et al. for an overview), but, as Kahneman (1999, p. 19) states, "the extent to which loss aversion is also found in experience is not yet known". In this context there is an interesting relationship with the dependence of happiness on the average income in a social reference group as postulated by Easterlin, Frank and others. Such a social reference income provides a natural reference point for people to compare their own income with. Income relative to this social reference income then corresponds to gains for positive values and to losses for negative values. Moreover, the asymmetry in the income comparison assumed by Duesenberry amounts to loss aversion in Kahneman and Tversky's theory. This raises the question whether the other characteristics of the value function like concavity for gains and convexity for losses may also apply to this dependence of happiness on relative income.

In this paper we test whether the characteristics of Kahneman and Tversky's value function hold for individual life satisfaction. A significant positive dependence of life satisfaction on relative income has been found in the econometric cross-section and panel studies of McBride (2001), Stutzer (2004), and Ferrer-i-Carbonell (2005). Furthermore, the last study finds support for the asymmetry 
postulate of Duesenberry. However, the measures for reference income that were used in the three studies have some drawbacks that we try to improve on by introducing a refined measure. With this new measure we then test all the characteristics of Kahneman and Tversky's value function mentioned for a large German panel (GSOEP) spanning the years 1984 to 2001.

To test for concavity in positive relative income and convexity in negative relative income, we need a more flexible specification of life satisfaction in terms of relative income than the usual logarithmic one since the latter is concave in negative as well as positive relative income. Moreover, the specification should allow for asymmetries in the income comparison. For these purposes an asymmetric power-function specification is chosen, which includes the logarithmic specification as a special case. We then find concavity of life satisfaction in positive relative income, but unexpectedly strongly significant concavity of life satisfaction in negative relative income as well. Moreover, under plausible assumptions about the cardinal properties of the 'true-life-satisfaction' scale, the latter result turns out to be robust to extreme distortions of the reported-life-satisfaction scale (such as suggested by Oswald, 2005). It entails a strong rejection of the hypothesized convexity and implies a rising marginal sensitivity of life satisfaction to more negative values of relative income. Although this result is in line with the standard assumption of diminishing marginal utility of income in microeconomics, the contradiction with the convexity suggested by prospect theory calls for an explanation. One possible explanation is that as a person's income falls increasingly short of that in the reference group, it becomes increasingly and more than proportionally hard to raise the funds to participate in the social activities of the reference group. This effect of rising marginal social participation costs of falls in relative income apparently dominates a possible social comparison effect of diminishing marginal sensitivity of life satisfaction to such falls, which is suggested by the theory of Kahneman and Tversky. Moreover, it is shown to imply significant loss aversion (in a wide sense and at least for larger losses).

The paper is structured as follows. Section 2 formulates the hypotheses to be tested, and Section 3 discusses the problems of testing cardinal properties of true life satisfaction and our way to tackle these problems. Next, in Section 4 the life satisfaction equations are presented, and in Section 5 the new reference group measure, data and estimation procedure are discussed. Section 6 presents and analyses the estimation results, and Section 7 analyses their robustness to distortions of the reportedlife-satisfaction scale and to various modifications. Finally, Section 8 discusses possible explanations and behavioural implications of the results, and Section 9 concludes. 


\section{Hypotheses}

\subsection{Empirical findings}

While the influence of social comparison on individual preferences in decision-making and on income and job satisfactions has already been investigated for quite some time (see Ferrer-i-Carbonell (2005) for a recent overview), econometric studies that estimate the impact of social comparison on individual life satisfaction are rather recent. In cross-section and panel studies for American, Swiss and German data McBride (2001), Stutzer (2004) and Ferrer-i-Carbonell (2005) find that overall life satisfaction of individuals negatively depends on the average (real) incomes in their social reference groups. Moreover, the difference between their own income and such social reference income turns out to be a more important determinant of individual life satisfaction than the absolute level of income. This difference between income and reference income is referred to as relative income.

The empirical findings on the impact of social comparison on individual preferences, income and job satisfactions, and life satisfaction are partially consistent with the more general value-function theory of Kahneman and Tversky (1979) for decisions under risk and of Tversky and Kahneman (1991) for riskless choice (see the latter paper for references). The social reference income provides a natural reference point for people, to which they compare their own income, and the asymmetry result of Ferrer-i-Carbonell suggests loss aversion. On the other hand, in contrast to Kahneman and Tversky's value-function theory, most studies employ a utility function that is concave in negative as well as positive relative income. ${ }^{2}$ The characteristics of the value function have been tested extensively for decision utility and psychological perceptions (see Köbberling et al. for an overview), but, as Kahneman (1999, p. 19) indicates and as far as we know, characteristics like loss aversion have not been tested for experienced utility as measured ex post.

Some indications on possible properties of such experienced utility are given by psychophysical experiments reported by Galanter (1990). In one such experiment subjects were asked to imagine that they lost $\$ 5$, and to name the amount of money they would have to lose to make them exactly twice as upset as losing $\$ 5$. The geometric means of the subjects' judgments was $\$ 21$, and fitting this to a power function of the form $U=-a M^{b}$ yielded an exponent $b$ equal to 0.54 . A variety of cross-modality matching experiments yielded similar values of $b$, always a bit greater than 0.5 , for losses, but for gains values of $b$ always a bit smaller than 0.5. In general, loss aversion was found, and this finding as well as those of concavity for gains and convexity for losses is consistent with the characteristics of Kahneman and Tversky's value function. ${ }^{3}$

\footnotetext{
${ }^{2}$ Clark and Oswald (1998) derive the behavioural implications of utility that is concave or convex in status (i.e., 'relative action' in analogy to relative income). See Sec. 8.2 for more details.

${ }^{3}$ Kahneman (1999, p. 19) claims that the difference in the estimates of exponent $b$ for gains and losses would not account for the extensive loss aversion observed in choice experiments. However, we did not find evidence for this claim in the analysis of Gallanter (see his Fig. 4).
} 
However, the utility that was measured in these experiments is not experienced utility as measured ex post, but rather experienced utility as imagined ex ante. In the terminology of Kahneman et al. (1997) this may be called predicted utility as distinct from experienced utility per se. It might be considered as an intermediate case between experienced utility and decision utility and may deviate from both. In this paper, we focus on experienced utility as measured ex post in surveys. More specifically, we test the characteristics of the value function for the shapes of life satisfaction functions for income levels above and below the average incomes in social reference groups.

\subsection{Hypotheses}

Based on Kahneman and Tversky's value function, the following hypotheses will be tested for experienced utility:

H1: Individual life satisfaction $(S)$ depends significantly negatively on the average (real) family income in a social reference group, controlling for (real) family income, family size and composition, and other relevant variables.

This hypothesis is based on what one would expect on the basis of psychological and sociological theories of social reference processes (e.g., Festinger, 1954), and has been confirmed by the empirical studies of McBride (2001), Stutzer (2004), and Ferrer-i-Carbonell (2005) cited above. On the other hand, Senik (2004) finds a significantly positive sign for Russian panel data, which she explains by the use of the informational content of changes in other people's incomes in forming one's own income expectations (see also Schyns, 2002). We consider family income instead of individual income for two reasons. First, on a conceptual level, family income may be a more adequate determinant of $S$ since the impact of income on $S$ runs primarily via individual consumption and this is related to family rather than individual income. Second, the dataset that we use (see Sec. 6) contains better data for family than for individual income. However, since the consumption out of the family income is divided over all household members, we control for number of adults and number of children in the household.

H2: $\quad S$ depends significantly positively on the difference between family income and the average family income in a social reference group (relative income), controlling for family income (absolute income), family size/composition, and other relevant variables.

This hypothesis corresponds to the reference dependence of Kahneman and Tversky's value function, and is explicitly confirmed by Ferrer-i-Carbonell (2005) (see Sec. 2.1). It allows to separate the 
influence on $S$ of the level of income relative to the social reference income from the impact of the absolute level of income.

H3: $\quad S$ depends significantly more positively on relative income than on absolute income.

This hypothesis investigates the dominance of reference dependence over reference-independent effects.

H4: $\quad S$ is concave in positive values of relative family income and convex in negative values of relative family income.

This hypothesis corresponds to the diminishing sensitivity of the marginal value of both gains and losses, which is implied by Kahneman and Tversky's value function and suggested by the results of Galanter reported above.

H5: The degree of concavity of $S$ in positive values of relative family income equals the degree of convexity in negative values of relative family income (for equal absolute magnitudes of negative and positive relative family income).

This hypothesis corresponds to the reflection effect with respect to gains and losses as hypothesized by Kahneman and Tversky (1979, pp. 268-269), which is distinguished from the asymmetry implied by loss aversion (see below). Several studies on decision utility suggest that the value function for gains and losses is fairly well approximated by power functions with similar exponents, both less than unity (Swalm, 1966; Tversky and Kahneman, 1992; Kahneman, 2003). These exponents reflect the degrees of concavity of the value function for gains and of convexity for losses. On the other hand, for the case of 'predicted utility' Galanter reports higher estimated exponents for losses than for gains (see Sec. 2.1). This suggests that experienced utility of money may be less convex in losses than it is concave in gains. For decision utility this is also hypothesized by Köbberling et al. (2004). They argue that the psychological perception-of-quantity effect as decribed by Kahneman and Tversky's value function is then confounded with the economic intrinsic-utility-of-money effect, which is assumed to exhibit diminishing marginal utility. This argument can explain Galanter et al.'s findings for 'predicted utility' as well. However, in the present life-satisfaction context the intrinsic-utility-of-money effect can be associated with the effect of absolute income on $S$, while the effect of relative income may be fully consistent with the characteristics of the value function, including the reflection effect. We therefore 
maintain hypothesis H5. Furthermore, because of the association of the absolute income effect with diminishing marginal intrinsic utility of money we hypothesize:

H6: $\quad S$ is concave in (positive values of) absolute family income.

Finally,

H7: $\quad S$ as a function of relative income is significantly steeper for negative values of relative income than for positive values (at equal absolute magnitudes of negative and positive relative income).

This hypothesis corresponds to the loss aversion implied by Kahneman and Tversky's value function and suggested by the results of Galanter (see also Wakker and Tversky, 1993).

\section{Methodology}

\subsection{Limitations of probit analyses}

To test our hypotheses, first of all a reliable measure of life satisfaction is needed. Usually, such a measure involves a person's answer to a survey question about her/his overall life satisfaction. For example, in the GSOEP data set we use in this paper the satisfaction question is:

Please, answer according to the following scale: 0 means completely dissatisfied, 10 means completely satisfied.

How satisfied are you with your life, all things considered? ${ }^{4}$

The resulting score of reported life satisfaction $(R)$ can be considered as a reasonably reliable measure of a person's 'true' life satisfaction $(S)$, but the reliability of the score is limited by its discreteness and nonrandom measurement errors (see, e.g., Frey and Stutzer, 2002a, 2002b; Ferrer-i-Carbonell and Frijters, 2004; Luttmer, 2004).

First, we address the problem of discreteness of $R$. Following Blanchflower and Oswald (2004), we assume that a person's reported life satisfaction $R$ is a stepwise-increasing function $R_{0}(S)$ of her true life satisfaction or well-being $S$ plus a discrete measurement error term $e$. Function $R_{0}(S)$ is supposed to be the same for every individual in the survey. This implies that if $R_{0}\left(S_{i}\right)$ of individual $i$ is higher than $R_{0}\left(S_{j}\right)$ of individual $j, S_{i}$ is higher than $S_{j}$ (interpersonal ordinal comparability of $R_{0}(S)$; see assumption A2 of Ferrer-i-Carbonell and Frijters (2004)). However, individuals may make errors $e$ in

\footnotetext{
${ }^{4}$ This is the English translation in the GSOEP of 2001 of the German question. Surprisingly, in previous years the same question was translated in terms of 'unhappy' and 'happy' instead of 'dissatisfied' and 'satisfied' (see, e.g., Ferrer-i-Carbonell, 2005). We assume the more recent translation is the more correct one.
} 
reporting their true life satisfaction $S$. If these errors are randomly distributed among the individuals with average $\bar{e}=0$, the relation of $S$ to relative income and other explanatory variables can be estimated by an ordered probit or logit. The latent variable $Z$ is then considered as a proxy for the true well-being $S$ (Blanchflower and Oswald, 2004; Frey and Stutzer, 2002b, p. 406).

However, the question is whether this interpretation of $Z$ is valid not only in an ordinal, but also in a cardinal sense. The answer seems to be no since ordered probit or logit analysis only uses the ordinal information in the reported $R$ scores (Van Praag and Ferrer-i-Carbonell, 2004, p. 32; Ferrer-iCarbonell and Frijters, 2004, Sec. 3.2), and hence can never contain cardinal information on $R$, and so $S$. More specifically, probit (or logit) analysis is based on the assumption that reported $R$ is a stepwiseincreasing function $R(Z)$ of an underlying latent variable $Z$ ( $R=k$ if and only if $\lambda_{k} \leq Z<\lambda_{k+1}$ ). This function $R(Z)$ may differ from the stepwise-increasing function $R_{0}(S)$ as defined above $\mathrm{e}^{5}$, and it is easily shown that $Z$ can be any (continuously differentiable) monotonously increasing function of $S$. Ordinal properties of $S$ are then the same as the ordinal properties of $Z$, but cardinal properties of $S$ and $Z$ like concavity and convexity (see hypotheses H4-H6) may differ from each other.

A more adequate approach is cardinal probit or logit analysis, which makes use of the cardinal information in the reported $R$ scores as well (Van Praag and Ferrer-i-Carbonell, 2004, p. 32). A score $i$ of $R$ is then assumed to indicate that $S$ is in the interval $[i-0.5, i+0.5]$ (but in $[0,0.5]$ for $i=0$ and in $[9.5,10]$ for $i=10)$. This implies that the estimated threshold values $\lambda_{0}, \ldots, \lambda_{11}$ of latent variable $Z$ correspond to the values $0,0.5,1.5, \ldots, 9.5,10$, respectively, of $S$. We can then construct $S$ as a monotonously increasing function of $Z$. In general, this function tends to have a non-linear shape like that of a statistical distribution function. Therefore, Van Praag and Ferrer-i-Carbonell approximate this function by the standard-normal-distribution function. However, the non-linearity of such a function makes significance proofs of concavity/convexity of $S$ complicated and tedious.

\subsection{Least-squares regression with individual fixed effects}

With regard to concavity/convexity of $S$, a direct regression of reported life satisfaction $R$ on relative income and the other explanatory variables is much simpler and intuitively easier to interpret. We should then make the assumption that the stepwise-increasing function $R_{0}(S)$ correctly reflects the cardinal structure of $S$, i.e. the intervals of $S$ that are mapped onto the step levels $i=1, \ldots, 10$ have equal width (as in the special case of the above cardinal-probit assumption). Again assuming that measurement error $e$ is random, an imaginary regression of $R$ on $S$ that allows for a non-linear as well

\footnotetext{
${ }^{5}$ In fact, the ordered-probit estimation selects those threshold values $\lambda_{0}, \ldots, \lambda_{11}$ of $Z$ that give an optimal fit of the data to the (log)linear equation for $Z$. These estimates of $\lambda_{i}$ imply a certain shape of $R(Z)$ which may be different from the unknown shape of $R_{0}(S)$.
} 
as linear shape of the relation would then yield a linear relation (see assumption A3 and its plausibility arguments in Ferrer-i-Carbonell and Frijters (2004)).

However, a general drawback of the usual LS of a loglinear specification is that it in principle requires estimation on the real axis, whereas the range of $R$ scores is bounded between 0 and 10 . This may be remedied by regressing a logit or lognormal specification, but then significance proofs again become tedious. Moreover, a loglinear specification may give a good approximation since the variation in $R$ that is explained by the explanatory variables is small relative to the $[0,10]$ scale. In the case of LS with individual fixed effects (which we apply in this paper), the loglinear specification may, for each individual, be considered as a first-order Taylor expansion in the ln explanatory variables $(X)$ around an individual-specific baseline level of well-being that is determined by the value of the individual fixed effect (cf. Frey and Stutzer, 2002b, p. 407). Regressing the loglinear specification over all individuals in the sample then amounts to averaging the coefficients of $X$ over all these individual first-order Taylor expansions.

We include individual fixed effects to account for differences in personality characteristics, which explain the larger part of the total variation in happiness (see Kahneman et al., 1999). Applying LS with individual fixed effects implies that only the variation of $R$ with $X$ over time is estimated (within effects). This has certain disadvantages (see Sec. 5.2), but a great advantage in the present context is that it seems to require only intertemporal cardinal comparability of $R$ scores (as in intertemporal utility-maximizing models), but no interpersonal cardinal or ordinal comparability of $R$. This is because the individual fixed effects also correct for differences in the levels at which individuals "anchor" their $R$ scale (Winkelmann and Winkelmann, 1998). This measurement error may not be random but correlated with explanatory variables like income, educational level, and gender (e.g. via personal characteristics like optimism and intelligence; Johansson-Stenman and Martinsson, 2005). This causes the regression coefficients to be biased in the absence of individual fixed effects. Thus, controlling for such effects implies a strong unbiased test of properties like concavity of $R$ in $X$, which seems to avoid the problematic assumption of interpersonal comparability of $R$ scores. Because of this advantage, we adopt least squares estimation of $R(X)$ with individual fixed effects as our baseline estimation.

\subsection{Cultural norms}

Although individual fixed effects correct for some important nonrandom measurement errors $e$ that individuals make in reporting their true life satisfaction $S$, they do not control for all. In particular, there may be cultural norms that lead people to systematically overestimate or underestimate their happiness in certain domains of the scale (see, e.g., Johansson-Stenman and Martinsson, 2005). This may especially affect cardinal properties of the life satisfaction function like concavity and convexity. 
For instance, consider a culture (like perhaps the British) where people are reluctant to give a high assessment of their happiness (Oswald, 2005). ${ }^{6}$ This will lead to an underestimation of high values of $S$, implying a systematic downward bias of $R$ and a concave shape of the regression relation between $R$ and $S$ (see above). Estimated concavity of $R$ in relative or absolute income $Y$ could then be due to a comparable degree of concavity of the estimated $\hat{R}$ in $S$, leaving no (significant) concavity of true life satisfaction $S$ in $Y$. This can be seen by writing $\hat{R}(Y)$ as $\hat{R}(S(Y)$ ) (see Oswald, 2005, for a formal proof, and see Sec. 7.1 for more details). On the basis of this possibility Oswald concludes that the usual finding of diminishing returns of income in happiness research does not prove diminishing marginal utility. Moreover, in the context of our study, it seems to dismiss regressions of reported life satisfaction $R$ on relative and absolute income as a reliable means to test hypotheses H4-H6.

However, we can ask how strong concavity of estimated $\hat{R}$ in $S$ might be. This question is investigated in Section 7.1. Under plausible assumptions it is shown there that extreme distortions like that envisioned by Oswald imply degrees of concavity that are still significantly lower than estimated degrees of concavity of $R$ in relative income according to least squares estimation (LS). This result implies that estimated significant concavity of $R$ in relative income according to LS cannot be (fully) explained by possible concavity of $\hat{R}$ in $S$, and hence implies significant concavity of $S$ in relative income. Thus, even in the presence of distorting cultural norms we can rely on LS regressions of $R(X)$ to test hypotheses H4-H6.

\section{Life satisfaction equations}

\subsection{Specifications}

The usual specification used in econometric work on life satisfaction and social reference income (e.g., Ferrer-i-Carbonell, 2004) is:

$$
R=\alpha+\widetilde{\beta} \ln Y-\gamma \ln Y_{r}+\delta X+e,
$$

where $Y$ is family income, $Y_{r}$ is the average family income in a social reference group, $X$ is a vector of control variables, $e$ is an error term, and the Greek symbols stand for parameters. Parameters $\widetilde{\beta}$ and $\gamma$ are supposed to be non-negative and $\delta$ is a vector of parameters. Equation (1) can be rewritten as

$$
R=\alpha+(\widetilde{\beta}-\gamma) \ln Y+\gamma\left(\ln Y-\ln Y_{r}\right)+\delta X+e,
$$

which separates the relative income effect of $\ln Y-\ln Y_{r}$ from the absolute income effect of $\ln Y$. The former variable can also be written as $\ln \left(Y / Y_{r}\right)$, and the absolute-income coefficient $\widetilde{\beta}-\gamma$ is denoted as $\beta$.

In the context of Kahneman and Tversky's value-function theory $Y-Y_{r}$ seems the relevant variable, but $\ln \left(Y / Y_{r}\right)$ can be rewritten as $\ln \left[1+\left(Y / Y_{r}-1\right)\right]=\ln \left[1+\left(Y-Y_{r}\right) / Y_{r}\right]$, i.e. as a

\footnotetext{
${ }^{6}$ It is interesting to note that a similar reluctance to give high grades is found in the grading system at British universities, where an 8 tends to be the virtual maximum on a [0-10] scale (Sugden, personal communication).
} 
monotonously increasing function of $\left(Y-Y_{r}\right) / Y_{r}$. This $\left(Y-Y_{r}\right) / Y_{r}$ indicates gains and losses as (percentual) fractions of $Y_{r}$. In the present context of a variable reference income $Y_{r}$ (as opposed to prospect theory), the fractional gains and losses $\left(Y-Y_{r}\right) / Y_{r}$ seem even more relevant determinants of life satisfaction than the 'absolute' gains and losses $Y-Y_{r}$. We denote the relative income gap $\left(Y-Y_{r}\right) / Y_{r}$ as $G$. Hence, specifications (1) and (2) can be used to test hypotheses H1-H3. However, specification (2) cannot be used to test hypotheses $\mathrm{H} 4$ and $\mathrm{H} 5$ since it is concave in $G$ for losses as well as gains. For that purpose, we nest specification (2) into a more flexible power-function specification that is given by

$$
R=\alpha+\beta \ln Y+\gamma \frac{\left(Y / Y_{r}\right)^{1-\rho}-1}{1-\rho}+\delta X+e, \quad \rho \neq 1 .
$$

Here the power-function term approaches $\ln \left(Y / Y_{r}\right)$ for $\rho \rightarrow 1$. Rewriting the power function term as $\gamma\left[\left(1+\left(Y-Y_{r}\right) / Y_{r}\right)^{1-\rho}-1\right] /(1-\rho)$, it is easily seen that it is concave in $G \equiv\left(Y-Y_{r}\right) / Y_{r}$ for $\rho>0$ and convex in $G$ for $\rho<0$. Concavity of $S$ in positive $G$ and convexity of $S$ in negative $G$ can then be tested as follows. First, we define positive relative income $G_{+}$, respectively negative relative income $G_{-}$as equal to $G$ for positive, respectively negative values of $G$, but as equal to zero for negative, respectively positive values of $G$ (cf. Ferrer-i-Carbonell). Then, we modify specification (3) as

$$
R=\alpha+\beta \ln Y+\gamma_{+} \frac{\left(1+G_{+}\right)^{1-\rho_{+}}-1}{1-\rho_{+}}+\gamma_{-} \frac{\left(1+G_{-}\right)^{1-\rho_{-}}-1}{1-\rho_{-}}+\delta X+e,
$$

where we allow for different parameters $\gamma_{+}$and $\gamma_{-}$(see below) as well as $\rho_{+}$and $\rho_{-}$. Concavity of $S$ in $G_{+}$and convexity of $S$ in $G_{-}$then correspond to $\rho_{+}>0$ and $\rho_{-}<0$.

\subsection{Parameter inequalities implied by hypotheses}

Assuming that reported life satisfaction $R$ is a good proxy for true life satisfaction $S$ (see Sec. 3.3), the hypotheses in Section 2 imply the following inequalities for the parameters in specifications (1)-(4). Hypothesis $\mathrm{H} 1$ corresponds to a significantly positive value of $\gamma$ in specification (1), and $\mathrm{H} 2$ to significantly positive values of $\gamma$ in specifications (2) and (3) and of $\gamma_{+}$and $\gamma_{-}$in specification (4). Hypothesis $\mathrm{H} 3$ corresponds to a significantly positive values of $\gamma-\beta \equiv 2 \gamma-\widetilde{\beta}$ in specification (2).

Hypothesis H4 (concavity in gains and convexity in losses) corresponds to $\rho_{+}$being significantly positive and $\rho_{-}$being significantly negative in specification (4). For hypothesis H5 (equal degrees of concavity in gains and convexity in losses) we need a measure for concavity and convexity. For our power function specification a convenient (though somewhat arbitrary) measure is $\rho_{ \pm}$, which equals Pratt's measure of relative risk aversion/loving $\operatorname{rr}\left(Y / Y_{r}\right) \equiv$ $-\left(Y / Y_{r}\right)\left(\partial^{2} R / \partial\left(Y / Y_{r}\right)^{2}\right) /\left(\partial R / \partial\left(Y / Y_{r}\right)\right)$ for $Y \geq Y_{r}$ and $Y \leq Y_{r}$, respectively. This is a commonly 
used index to describe curvature of utility. ${ }^{7}$ Hypothesis H5 then implies that $\rho_{-}$should not differ significantly from $-\rho_{+}$. To test the concavity of $S$ in absolute family income (hypothesis H6), we replace the term $\beta \ln Y$ in specification (4) by the more flexible term $\beta\left(Y^{1-\sigma}-1\right) /(1-\sigma), \sigma \neq 1$ (which approaches $\beta \ln Y$ for $\sigma \rightarrow 1$ ), and estimate whether $\sigma$ is significantly positive while $\beta$ is significantly positive as well.

Hypothesis H7 (loss aversion, i.e. steeper slope for losses than for gains) is consistent with a significantly positive value of $\gamma$ in specification (2) and significantly positive values of $\gamma$ and $\rho$ (concavity) in specification (3) since the marginal utility of relative income $G \equiv\left(Y-Y_{r}\right) / Y_{r}$ then rises as $G$ falls from positive to negative values. However, usually loss aversion is associated with a kink in the slope of the value function at the origin with a steeper slope for losses (see Kahneman, Knetsch and Thaler, 1991). Köbberling and Wakker (2005) even restrict their definition of loss aversion to this discontinuity property. In specification (4) it corresponds to a discontinuity in the slope $\partial R / \partial G_{ \pm}=\gamma_{ \pm}\left(1+G_{ \pm}\right)^{-\rho_{ \pm}}=\gamma_{ \pm}$at $G_{ \pm}=0$ with $\gamma_{-}>\gamma_{+}$. In the context of our study it is more appropriate to use the wider definition of loss aversion that is expressed in hypothesis $\mathrm{H} 7$ and that is already implied by concavity of $R$ in $G_{+}$and $G_{-}$without any discontuinity in the slope. Such 'elementary' loss aversion is sufficient for an asymmetry in the social comparison similar to that postulated by Duesenberry (1949) to emerge. In the context of risk behaviour it causes risk aversion (see Sec. 8.2 and Köbberling and Wakker, 2005). In general, specification (4) implies loss aversion in this wide sense for all positive values of $\left|G_{-}\right|=G_{+}$if $\gamma_{-} \geq \gamma_{+}, \rho_{+}>0$ and $\rho_{-}>0$ (concavity in gains as well as losses). However, if hypothesis H4 (concavity in gains and convexity in losses) holds, this condition cannot be fulfilled since $\rho_{-}$will then be negative. Fulfilment of hypothesis $\mathrm{H} 7$ then depends on the values of $\gamma_{-}$and $\rho_{-}$relative to $\gamma_{+}$and $\rho_{+}$and of $\left|G_{-}\right|=G_{+} \equiv G$ in a complicated way according to the slope condition $\partial R / \partial G_{-}(-G)>\partial R / \partial G_{+}(G)$. On the other hand, if hypothesis $\mathrm{H} 4$ is rejected, matters may become less complicated (see Sec. 6.1).

A stronger version of hypothesis $\mathrm{H} 7$ is that this slope condition also holds in the limit for $G$ approaching zero. This implies a kink in the satisfaction function for $G=0$, and so a significantly higher value of $\gamma_{-}$than the value of $\gamma_{+}$(see above). The postulate of Duesenberry (1949) that richer people do not become happier from comparing their income with that of poorer members of their reference group even implies that $\gamma_{+}$should not differ significantly from zero (cf. Ferrer-i-Carbonell, 2005).

\footnotetext{
${ }^{7}$ Note, however, that this measure is defined in terms of $Y / Y_{r}$, and so not in terms of $G_{+}$and $G_{-}$. See Sec. 8.2 for more on this.
} 


\subsection{Comparison with specification used in prospect theory}

It is interesting to note that the power-function specification used in this study differs from that employed by Galanter (1990) and Tversky and Kahneman (1992, p. 309). In the present context the latter specification would amount to terms $\gamma_{+} G_{+}{ }^{1-\rho_{+}}$and $-\gamma_{-}\left(-G_{-}\right)^{1+\rho_{-}}$for the relative income effects in specification (4), where $\gamma_{+}, \gamma_{-}$, and $\rho_{+}$are supposed to be positive and $\rho_{-}$negative (convexity). ${ }^{8}$ For decision utility Tversky and Kahneman obtained parameter estimates that for these relative income terms would imply that $\rho_{+}=0.12$ and $\rho_{-}=-0.12$, and that $\gamma_{-}$is more than twice as high as $\gamma_{+}$. This would imply equal degrees of concavity in gains and convexity in losses (H4, H5) and loss aversion (H7). For 'predicted utility' Galanter calculated parameter values that in our context would imply that $\rho_{+}=0.55$ and $\rho_{-}=-0.45$ (the relative size of $\gamma_{+}$and $\gamma_{-}$cannot meaningfully be inferred because of different scaling in combination with $\rho_{-} \neq-\rho_{+}$). Hence, we would again have concavity in gains and convexity in losses (H4), but not equal in degree (H5). Furthermore, in the context of Galanter's utility function loss aversion can easily be shown to hold except for very small values of money.

However, in contrast to specification (4), the Galanter and Tversky and Kahneman (GTK) specification has the drawback of a lack of flexibility: For $G_{+}$and $G_{-}$approaching zero the slopes $\partial R / \partial G_{+}=\gamma_{+}\left(1-\rho_{+}\right) G_{+}{ }^{-\rho_{+}}$and $\partial R / \partial G_{-}=\gamma_{-}\left(1+\rho_{-}\right)\left(-G_{-}\right)^{\rho_{-}}$go to $\infty$ for $\rho_{+}>0$ and $\rho_{-}<0$, but to 0 for $\rho_{+}<0$ and $\rho_{-}>0$ (see also Köbberling and Wakker, 2005), while the slopes $\partial R / \partial G_{ \pm}$ according to specification (4) equal $\gamma_{ \pm}$at $G_{+}=G_{-}=0$ for any values of $\rho_{+}$and $\rho_{-}$. Hence, in the former as opposed to the latter case the slopes at $G_{+}=G_{-}=0$ do not vary continuously and independently from the concavity and convexity parameters $\rho_{+}$and $\rho_{-}$. Another drawback of the GTK specification in the present context is that, in contrast to specification (4), it does not include the asymmetric variant of the usual loglinear specification (2) (cf. Ferrer-i-Carbonell) as a special or limiting case.

\section{Operationalization of variables and estimation procedure}

\subsection{Measure for social reference income}

An important question is how to define the (social) reference group(s) of a person, i.e. who belongs to his/her reference group(s). The reference group that has the strongest influence on the person is likely to be the social group to which the individual belongs and which consists of people of similar age, education, income, region of residence, etc. (Ferrer-i-Carbonell, 2005; cf. Senik, 2004). In addition, there will be a less strong influence from wider groups like the person's community or region of residence (Diener et al., 1993; Stutzer, 2004), the person's cohort (McBride, 2001), or the person's

\footnotetext{
${ }^{8}$ Taking $G_{ \pm} \equiv\left(Y-Y_{r}\right) / Y_{r}$ instead of $Y-Y_{r}$ in the specification only amounts to a rescaling by a factor $1 / Y_{r}$, which is fixed in the context of prospect theory.
} 
country (Easterlin, 1995). Thus, in general there will be more than one reference group the average income of which can be assumed to affect a person's life satisfaction (see Kapteyn and Wansbeek, 1985; Vendrik and Hirata, 2003). However, in econometric research it is usually assumed that there is only one reference group which is either identified as the social group of the person (Ferrer-iCarbonell) or approximated by one of the wider groups mentioned above.

Ferrer-i-Carbonell uses education, age, and region as reference group categories. Her reference group contains all individuals with a similar education level, inside the same age bracket, and living in the same region (West or East Germany for Ferrer-i-Carbonell's German data). The five different education categories are: less than 10,10,11,12, and more than 12 years of education, and the age brackets are: younger than $25,25-34,35-44,45-65$, and 66 years or older. This leads to 50 different (exogenous) reference groups. However, this measure has the drawback that the age brackets are fixed. This implies, for instance, that when a person becomes 35 years old, his/her reference group suddenly changes from 25-34 to 35-44 years old. This is, of course, implausible, and in this respect the measure used by McBride (2002) is better. For USA data, he approximates the influence from the reference group by the average income in a person's cohort consisting of everyone from 5 years younger than the person to 5 years older. Thus, this reference group moves along with the age of the person. On the other hand, a severe downside of this measure is that it does not distinguish between different education categories, as Ferrer-i-Carbonell's measure does. Therefore, in this paper we introduce a new measure which combines the best of both measures, i.e. a moving age bracket as McBride's in combination with the education and region categories of Ferrer-i-Carbonell and gender. We added gender since especially men may primarily be influenced by the family income of other men.

\subsection{Data, variables and estimation procedure}

The database used for all estimations is the German Socio-Economic Panel (GSOEP; see Wagner et al., 1993; Kroh and Spiess, 2005). The panel covers the years 1984-2001 for West Germany and 19912001 for East Germany. The sample includes about 16000 individuals who stayed on average more than eight years in the panel. For most households all individuals are in the sample. The number of missing observations for the variables we use is less than $3 \%$.

The dependent variable used in all estimations is reported individual life satisfaction (see Sec. 3.1). The main independent variable is real family income, i.e. family income corrected for the consumer price index. For social reference income we calculated the refined measure introduced in the previous section. As control variables we use more or less the standard variables: First, the number of adults and children in the households (see Sec. 2.2); second, the number of years of education, since people with a higher educational level may have more skills to become happy; third, unemployment, since unemployed people will have a lower level of life satisfaction; fourth, ln age to capture a 
possible nonlinear effect of age on life satisfaction'; fifth, a number of dummies for family situation (married without children, single parent, married with children up to or higher than sixteen years old); and finally, working hours with a dummy for missing observations. Time-invariant variables like gender are not included, because we estimate with fixed individual effects that catch the effect of these variables.

For our baseline estimations we apply non-linear least squares with fixed time and fixed individual effects. We include fixed time effects to account for period effects on happiness. For example, people may be influenced by the phase of the business cycle, events in history like the reunion of Germany, and the price index may not always be adequate to calculate real income. We use fixed individual effects for two related reasons: First, by only estimating the variation of life satisfaction with explanatory variables over time (within effects), we seem to avoid the problematic assumption of interpersonal comparability of life satisfaction scores (see Sec. 3.2). Second and more generally, we prevent biases due to unobserved personality traits like optimism and intelligence affecting at the same time life satisfaction and explanatory variables like income and educational level, giving rise to spurious correlations between life satisfaction and these variables. On the other hand, estimating only within effects means that the information from between effects of interpersonal variation is not used. As noted above, this eliminates the impact of time-invariant explanatory variables like gender and greatly reduces that of age. In a dynamic context it means that primarily short-run shock effects are estimated, implying a potential under or overestimation of long-run level effects of explanatory variables (Van Praag et al., 2003; Van Praag and Ferrer-i-Carbonell, 2004, p. 50). For that reason, we also run estimations with random individual effects (but fixed time effects) as a robustness check of the results from the baseline estimations with fixed individual effects (see Sec. 7.2).

\section{Estimation results}

\subsection{Tests of hypotheses}

This section presents estimation results for our new reference group measure. We restrict ourselves in this section to the West-German sample because the transformation process in Eastern Germany may have generated less stable behaviour over time when the former country was adapting to its new situation (see Sec. 7.2 for results for Eastern Germany). We focus on the coefficients that are relevant for testing the hypotheses. The other coefficients will be discussed as far as they yield unexpected results.

\footnotetext{
${ }^{9}$ We estimate with fixed individual and time effects, which catch the effect of the variation of age between individuals and the linear part of the intertemporal effect, respectively (see below). An additional ln age term can account for a possible (inverted-) U-shape of life satisfaction as a function of age as found in the literature (see Ferrer-i-Carbonell and Frijters, 2004).
} 
To test hypothesis H1 we estimated equation (1) with the logarithmic specification of the impact of social reference income. The estimated coefficients are presented in the first column of Table 1. The coefficient $\gamma$ of $\ln Y_{r}$ (social reference income) is indeed negative and very significant. Thus, hypothesis $\mathrm{H} 1$ is confirmed. Moreover, $\gamma$ is strikingly similar in absolute magnitude to the coefficient $\widetilde{\beta}$ of $\ln Y$ (family income). The size 0.31 of $\widetilde{\beta}$ indicates that a ceteris paribus increase in family income by $10 \%$ would raise life satisfaction $R$ of the average West German individual by 0.031 . On the other hand, if at the same time the family income of people in the social reference group rises by the same $10 \%$, implying a rise in $Y_{r}$ by $10 \%$, this would lower $R$ by the same amount. The net effect of these rises in $Y$ and $Y_{r}$ on $R$ would then be zero! In a nutshell this explains the empirical finding of no effect of income growth on average happiness in Germany (as in most other developed countries) over time (Glatzer, 1991; Easterlin, 1974, 1995). Note that the separate effects of such rises in $Y$ and $Y_{r}$ on life satisfaction are small, but very significant. Here one should keep in mind that income is only one of the many determinants of life satisfaction (see also Ferrer-i-Carbonell, 2005).

Further note that the coefficients of the other determinants in Table 1 have plausible and mostly significant values. Unemployment has a strongly significant and sizable negative effect (as found in other studies as well; e.g., Winkelmann and Winkelmann (1998)), while ln(age) has a strongly significant positive effect. Years of education and weekly hours have no significant effect. All these effects only reflect the variation of life satisfaction with the explanatory variables over time because of the inclusion of individual fixed effects. Moreover, the linear part of the intertemporal effect of age is caught by the fixed time effects. The coefficients of the corresponding year dummies, which are not presented in Table 1, are all strongly significant and reveal a negative time trend in life satisfaction (slope about -0.07). As far as this time trend represents negative effects of rising age it counteracts the positive $\ln$ age term. The concavity of this term in age in combination with the negative time trend is consistent with either an inverted U-shape of $R$ as a function of age or a monotonously falling $R$ with age at an increasing rate. ${ }^{10}$

Hypothesis H2 was tested using equation (2) with the logarithmic specification of the effect of relative income as well as equations (3) and (4) with the power-function specification. The estimates for equation (2), as presented in the second column of Table 1, show that the coefficient $\gamma$ of $\ln$ (relative family income) is indeed positive and very significant. In fact, by definition all coefficients except that for absolute income are identical to the corresponding coefficients for equation (1). Note that with relative income in the equation the coefficient of absolute income becomes insignificant. In equation (3) (see the first column of Table 2) the coefficient $\gamma$ of the relative income term is

\footnotetext{
${ }^{10}$ If the negative time trend exactly captures the negative age effects, $R$ is decreasing in age from a maximum at about 18 years. This is in line with the findings for GSOEP data of Ferrer-i-Carbonell and Frijters (2004) and Winkelmann and Winkelmann (1998), but in contradiction with that of Ferrer-i-Carbonell (2005).
} 
significantly positive as well. For the asymmetric specification (4) (second column of Table 2) we estimated $\gamma_{+}=0.293$ and $\gamma_{-}=0.404$, which are both significantly positive. Thus, hypothesis $\mathrm{H} 2$ was confirmed for all specifications.

The estimates of the coefficients for relative and absolute income in equation (2) strongly suggest that they differ significantly (hypothesis H3). A Wald test indeed showed this marginally to hold $(\mathrm{p}=0.06)$, thus giving support to hypothesis $\mathrm{H} 3$.

Unexpectedly, hypothesis H4 (concavity in gains and convexity in losses) is only partially supported by the estimates of $\rho_{+}$and $\rho_{-}$in equation (4): $\rho_{+}=1.928$ is considerably higher than zero, but not significantly so due to a large standard error, and $\rho_{-}=0.785$ is significantly positive (see Appendix A for details of the non-linear estimation procedure). This implies insignificant concavity of life satisfaction in positive relative income and significant concavity of life satisfaction in negative relative income. However, because of the nonlinear dependence of $R$ on $\rho_{+}$and $\rho_{-}$, we also applied likelihood-ratio tests to test the significance of the positivity of $\rho_{+}$and $\rho_{-}$(see Appendix A). This yielded the result that not only $\rho_{-}$, but also $\rho_{+}$is significantly positive, in contradiction to the t-test result! This contradiction stems from bimodality of the log-likelihood function and is a well-known phenomenon in non-linear estimation. In general, it does not seem to be justified to trust one test result more than the other, but in this case of bimodality of the log-likelihood function, the likelihood-ratio test seems to make more sense. This would imply that life satisfaction is significantly concave in positive relative income as well. The concavity of life satisfaction in negative as well as positive relative income is shown in Figure 1, which represents the dependence of life satisfaction on relative income $G$ for the average West German individual in the 1984-2001 sample according to the estimated equation (4).

Insert Fig. 1 here

Hypothesis H5 (equal degrees of concavity in gains and convexity in losses) is obviously rejected since $R$ is significantly concave in negative relative income. On the other hand, the estimated exponents $\rho_{+}=1.928$ and $\rho_{-}=0.785$ suggest that $R$ is more concave in positive relative income than it is in negative relative income. However, due to the large standard error in $\rho_{+}$, the t-value of the difference in degree of concavity $\rho_{+}-\rho_{-}$is 1.02 , implying no significant difference. On the other hand, a likelihood-ratio test of $\quad \mathrm{H}_{0}: \quad \rho_{+}-\rho_{-}=0 \quad$ yielded $2|\ln L(1.928,0.785)-\ln L(0.8,0.8)|=5.36>3.86$, and so a significant difference in degree of concavity. Thus, according to this test, $R$ is significantly more concave in positive relative income than it is in negative relative income. 
A test of hypothesis H6 (concavity in absolute income) seems to be dubious because the coefficient of absolute income is not significant at all. To check this, we estimated specification (4) with the term $\beta\left(Y^{1-\sigma}-1\right) /(1-\sigma), \sigma \neq 1$, instead of $\beta \ln Y$ for a grid of fixed values of $\sigma$ between -2.5 and 7.6. This yielded the surprising result that the loglikelihood is maximal for $\sigma \geq 7.6$, with $\beta$ significantly negative. Thus, $R$ is decreasing and convex in absolute income, implying a strong rejection of hypothesis H6. This implausible result may be caused by multicollinearity with the positive relative income term, which had a higher $\gamma_{+}$and $\rho_{+}$than in the baseline estimation.

Hypothesis H7 (loss aversion, i.e. steeper slope for losses than for gains) is confirmed for equations (2) as well as (3) due to the concavity in relative income $(\rho=1.095>0$ in eq. (3)). For equation (4) we found $\gamma_{-}>\gamma_{+}, \rho_{+}>0$ and $\rho_{-}>0$, implying loss aversion. However, this loss aversion is not significant for all values of $\left|G_{-}\right|=G_{+}$since $\gamma_{-}$is not significantly greater than $\gamma_{+}$(tvalue of $\gamma_{-}-\gamma_{+}$is 0.6 ) and $\rho_{+}$may not be significantly positive (see above). Therefore, we performed Wald tests on the slope condition $\partial S / \partial G_{-}(-G)=\gamma_{-}(1-G)^{-\rho_{-}}>$ $\partial S / \partial G_{+}(G)=\gamma_{+}(1+G)^{-\rho_{+}}$for fixed values of $G$. This indicated that the slope condition is significant for $G \geq 0.16$, so for incomes at least $16 \%$ higher or lower than the reference income (note that $\partial S / \partial G_{-}(-G)=\gamma_{-}(1-G)^{-\rho_{-}}$approaches $\infty$ for $G$ going to one). Since the outcome of the Wald test for a nonlinear parameter restriction tends to depend on the specification of the restriction, we also did the test for the $\ln$ of the slope condition. This indicated significance of the slope condition for $G \geq 0.12$, so for somewhat lower values of $G$ than above. For our sample considerably less than $50 \%$ of the individuals are in these domains. Since the insignificance of $\gamma_{-}-\gamma_{+}$may be due to the simultaneous estimation of $\gamma_{+}$and $\gamma_{-}$with $\rho_{+}$and $\rho_{-}$we also estimated equation (4) with fixed optimal values $\rho_{+}=1.928$ and $\rho_{-}=0.785$. The difference between the estimated $\gamma_{+}=0.293$ and $\gamma_{-}=0.404$ then turned out to be marginally significant $(\mathrm{t}$-value $=1.71, \mathrm{p}$-value $=0.086)$. This implies (marginally) significant loss aversion for all values of $\left|G_{-}\right|=G_{+}$if we assume that the concavity in positive relative income is significant, as suggested by the pertinent likelihood-ratio test (see above). This would then confirm Duesenberry's asymmetry postulate except that the impact of positive relative income is still significant. However, the test results on loss aversion are mixed.

\subsection{Tests of specifications}

In testing the hypotheses we used the rather flexible specification (4) as well as the more restricted specifications (1)-(3). This raises the question whether the latter specifications are not too restrictive, i.e. whether they are rejected against the more general specification (4). First, a Wald test as well as a likelihood-ratio test of the joint restrictions $\gamma_{-}-\gamma_{+}=0$ and $\rho_{-}-\rho_{+}=0$ in equation (4) yields a clear rejection ( $p=0.018$ for the Wald test), although the separate restrictions are not rejected by t-tests (see 
above). Thus, we can conclude that asymmetric specification (4) gives a significantly better fit of the data than symmetric specification (3).

Second, we tested whether the power-function specification in equation (4) fits significantly better than the corresponding asymmetric variant of the logarithmic equation (2) (third column of Table 1; cf. Ferrer-i-Carbonell, 2005, fourth specification). A Wald test does not reject joint restrictions $\rho_{-}-\rho_{+}=0$ and $\rho_{-}-1=0$ in equation (4) $(p=0.101)$, but a likelihood-ratio test does. Thus, there is mixed evidence whether the asymmetric power-function specification fits significantly better than the asymmetric logarithmic one. Because of this mixed evidence we also tested for a significant difference between the latter specification and the symmetric logarithmic specification (2). Both a t-test and a likelihood-ratio test reject restriction $\gamma_{-}-\gamma_{+}=0(\mathrm{t}$-value $=3.1)$, again indicating the superiority of the asymmetric specification. In general, we can conclude that specification (4) is more suitable than the other specifications to test hypotheses H2 and H7 (and of course H4 and H5).

\section{Robustness}

\subsection{Distortions of reported-life-satisfaction scale}

Do the significant cardinal properties of reported life satisfaction $R$ as a function of negative and positive relative income that we have found in our estimations imply similar cardinal properties of true life satisfaction $S$ ? In particular, does the estimated significant concavity of $R$ in negative (and positive) relative income reflect similar concavity of $S$, or can it be explained by possible concavity of "OLS-estimated" $\hat{R}$ in $S$ ? To make this investigation tractable, we assume that the scale of true life satisfaction $S$ is continuous, bounded from above and below, and cardinal. Boundedness from above and below means that true life satisfaction has a maximum and a minimum value, corresponding to complete satisfaction and dissatisfaction, respectively. ${ }^{11}$ Without loss of generality, we can choose the scale of $S$ such that the maximum value of $S$ is 10 and its minimum value is 0 , so that $S$, just as $R$, has values from 0 to $10 .{ }^{12}$ Cardinality of this scale then means that a difference in $S$ between, say, 7.5 and 8.5 represents the same difference in satisfaction intensity for an individual as the difference between 5.5 and $6.5 .{ }^{13}$ Next, we assume that scores of reported life satisfaction $R$ deviate within certain extreme limits (to be specified below) from the levels of true life satisfaction $S$ that they report.

Deviations of $R$ from $S$ may give rise to estimated $\hat{R}$ being concave in $S$. In particular, as mentioned in Section 3.3, people may be reluctant to give a high assessment of their happiness

\footnotetext{
${ }^{11}$ Complete satisfaction and dissatisfaction are translations of 'ganz und gar zufrieden' and 'ganz und gar unzufrieden', respectively, in the German GSOEP formulation of the life satisfaction question. These terms clearly suggest that they correspond to maximum and minimum values of life satisfaction.

12 This scale can be obtained by applying a specific linear (i.e. affine) transformation to any other cardinal scale that $S$ happens to have. Cardinality of the scale is preserved under such a transformation.

13 Note that, in the present context of individual-fixed-effect estimations, this cardinal comparability of differences in $S$ only needs to hold for an individual over time, but not between individuals (see Sec. 3.2.).
} 
(Oswald, 2005). In the context of our assumptions on the scale of $S$, people who experience a true life satisfaction $S$ between 9.5 and the maximal value 10 may report this by a score of $R=8$ (in line with the British grading system, see footnote 6). However, Figure 2 shows that although most individuals in the West German sample reported $R=8$, there are also a lot of people who reported a 9 or 10 . This implies that even if a number of West Germans who experienced an $S$ between 8.5 and 10 reported $R=$ 8 , others did not. ${ }^{14}$ It might be possible that on average West Germans who experienced an $S$ between 9.5 and 10 reported around $R=9$, but an average score of $R=8$ for these people seems implausible. Let us therefore consider the former possibility of an average $R=9$ and construct a continuous concave function $\hat{R}(S)$ such that $\hat{R}(5)=5, \hat{R}(7)=7$ and $\hat{R}(10)=9$. For this we need a flexible function with at least three parameters. A suitable one turns out to be the power function $\hat{R}(S)=a(S-c)^{1-b}$ with parameters $a>0,0<b<1$ (concavity parameter) and $c>0$. The inverse of this function is the convex function $S(\hat{R})=\hat{R}^{1+r} / a^{1+r}+c$, where $r \equiv b /(1-b)>0$ (convexity parameter). As $\hat{R}=R-e$, it is given by the right-hand side of equation (4) minus $e$. Substituting this expression for $\hat{R}$ into the function $S(\hat{R})$ then yields $S$ as a function $S\left[\hat{R}\left(Y, G_{+}, G_{-}, X\right)\right]$ of $Y, G_{+}$, $G_{-}$, and $X$. What we want to know is whether, according to our estimated coefficients of equation (4), $S$ is significantly concave in $G_{-}$and $G_{+}$despite the convexity of $S(\hat{R})$. For that we need to investigate whether the second-order partial derivative $\partial^{2} S / \partial G_{\mp}{ }^{2}$ is significantly negative for all values of $G_{\mp}$ and $\hat{R} \geq 5(S(\hat{R})$ is likely to be less convex or even concave for $\hat{R}<5)$. First, the firstorder derivative $\partial S / \partial G_{\mp}$ can be derived as $\partial S / \partial G_{\mp}=(\partial S / \partial \hat{R})\left(\partial \hat{R} / \partial G_{\mp}\right)=$ $=(1+r) \hat{R}^{r} \gamma_{\mp}\left(1+G_{\mp}\right)^{-\rho_{\mp}} / a^{1+r}$. Differentiating this to $G_{\mp}$ and imposing negativity yields the condition $5 \rho_{\mp}>\gamma_{\mp}\left(1+G_{\mp}\right)^{1-\rho_{\mp}} r$

for all values of $G_{\mp}$. Here we substituted 5 for $\hat{R}$ since the condition for $\hat{R}=5$ implies the condition for $\hat{R}>5$. On the left-hand side of this equation we see the estimated degree of concavity $\rho_{\mp}$ of $\hat{R}$ in $G_{\mp}$, while on the right-hand side the degree of convexity $r$ of $S$ in $\hat{R}$ appears.

Insert Fig. 2 here

For negative relative income $\rho_{-}=0.785<1$, or $1-\rho_{-}>0$, implies $\left(1+G^{-}\right)^{1-\rho_{-}} \leq(1+0)^{1-\rho_{-}}=1$ for all $G_{-} \leq 0$, and hence fulfilment of condition (5) for all $G_{-} \leq 0$ if and only if it holds for $G_{-}=0$. Condition (5) then simplifies to $5 \rho_{-}>\gamma_{-} r$. This condition is satisfied for all values of $r$ such that $3.925>0.404 r$, i.e. for $r<9.72$. For positive relative income $\rho_{+}=1.928>1$, or $1-\rho_{+}<0$, implies $\left(1+G_{+}\right)^{1-\rho_{+}} \leq(1+0)^{1-\rho_{+}}=1$ for all $G_{+} \geq 0$, and hence fulfilment of condition

\footnotetext{
${ }^{14}$ People in Preussen in North Germany may be reluctant to report a high $R$, but people in Bayern (South Germany) and Rheinland-Westfalen (Western state) seem more straight in their reporting (Winfried Koeniger and Matthias Wibral, personal communication).
} 
(5) for all $G_{+} \geq 0$ if and only it holds for $G_{+}=0$. Condition (5) then simplifies to $5 \rho_{+}>\gamma_{+} r$. This condition is satisfied for values of $r$ such that $9.640>0.293 r$, i.e. for $r<32.24$. The three restrictions $\hat{R}(5)=5, \hat{R}(7)=7$, and $\hat{R}(10)=9$ for $\hat{R}(S)$ lead to a power equation in $r$ (see Appendix B) that can only be solved numerically and yielded a value $r=1.41$. This value satisfies the above conditions for $r$ for negative as well as positive income, implying that condition (5) is fulfilled for all $G_{\mp}$. Thus, for this rather extreme distortion of the reported life satisfaction scale condition (5) is fulfilled for negative as well as positive relative income (and $\hat{R} \geq 5$ ). Therefore, despite of the distortion true life satisfaction is concave in both domains. This even holds for the implausibly extreme concavity of $\hat{R}$ in $S$ that is implied by the restrictions $\hat{R}(5)=5, \hat{R}(7)=7$, and $\hat{R}(10)=8$, yielding $r=5.30$ (see Appendix B).

Another kind of distortion of the reported-life-satisfaction scale may arise from a cultural norm that one is supposed to be either very glad or very sad (Ferrer-i-Carbonell and Frijters, 2004; Frey and Stutzer, 2002a). Moderate values of $S$ above 5 are then overrated, whereas moderate values of $S$ below 5 are underrated. Although we did not find indications that this may hold for our German sample (see footnote 14), we cannot exclude this possibility. It leads to concavity of $\hat{R}$ in $S$ higher than 5 and to convexity of $\hat{R}$ in $S$ lower than 5 . The latter convexity implies that for $S$ lower than 5 the estimated significant concavity of $R$ in negative and positive relative income reflects even stronger concavity of $S$. Hence, the analysis can be confined to the implications of concavity of $\hat{R}$ in $S$ higher than 5. An extreme distortion occurs if on average West Germans who experienced an $S$ between 6.5 and 7.5 reported $R=8$. Combining this with the restrictions $\hat{R}(5)=5$ and $\hat{R}(10)=10$ yields $r=2.58$ (see Appendix B). This value again satisfies the above conditions for $r$ for negative as well as positive relative income, leading to the same conclusion that despite of the distortion true life satisfaction is concave in negative as well as positive relative income. ${ }^{15}$

However, for the concavity of $S$ in negative and positive relative income to be significant, condition (5) should be satisfied significantly. Therefore, for negative relative income we performed Wald tests on condition (5) for $r=1.41,2.58$, and 5.30, and various values of $G_{-}$between 0 and -1 . For $r=1.41$ (2.58) the $\mathrm{H}_{0}$ of equality was strongly rejected with $p$ ranging from $0.002(0.014)$ for $G_{-}=0$ to 0.000 for $G_{-}=-1$. On the other hand, for $r=5.30$ the $\mathrm{H}_{0}$ of equality was not rejected for $G_{-}=0(p=0.23)$, but only rejected for $G_{-} \leq-0.7$, which comprised very few observations. Thus, for negative relative income condition (5) is satisfied significantly for $r=1.41$ and $r=2.58$, but not for $r=$ 5.30. For positive relative income $\rho_{+}$is not significantly positive according to a t-test, or equivalently

${ }^{15}$ Concavity of $\hat{R}$ in high $S$ and convexity in low $S$ will also result from truncations of the measurement error $e$ in $R$ at scores near 10 and 0 due to the impossibility of scores higher than 10 or lower than 0 . However, the former concavity is likely to be weaker than that corresponding to $\hat{R}(10)=9$ as analysed above. It might also be possible that the $S$ scale is not bounded as assumed above, but extends to infinite values for $R=10$ and $R=0$. However, even then the resulting concavity seems weaker than that assumed above. 
Wald test (see Sec. 6.1). Therefore, Wald tests on the stronger concavity condition (5) will not reject the $\mathrm{H}_{0}$ of equality. However, we also did likelihood-ratio tests, which yielded the opposite result for $r$ =1.41, 2.58, and 5.30 (see Appendix B and cf. Sec. 6.1).

Summarizing, we can conclude that, according to our estimates of equation (4), true life satisfaction $S$ is significantly concave in negative relative income even in the presence of extreme concavities of reported life satisfaction $\hat{R}$ in $S$ as assumed above ( $r=1.41$ or 2.58 ). On the other hand, for positive relative income we can only conclude that $S$ is significantly concave on the basis of likelihood-ratio tests, but not on the basis of Wald tests.

\subsection{Alternative specifications, populations, and estimation procedure}

The control variables age and years of education are also determinants of our measure of social reference income (see Sec. 5.1). This may give problems of multicollinearity. In order to test for that we estimated equation (4) without either age or education or both. Omitting age does not essentially change the estimates for negative relative income, but it makes the coefficient $\gamma_{+}$of positive relative income insignificant (at a $p=0.05$ level), while the coefficient of absolute income becomes less insignificant (especially when education was omitted as well). The exponent $\rho_{+}$for positive relative income becomes even more positive, but remains insignificant (according to a t-test). Omitting only education does not affect the estimates for relative income. On the other hand, replacing ln age by age squared makes $\rho_{+}$as well as $\gamma_{+}$significantly positive and $\rho_{-}$and $\gamma_{-}$even more significantly positive than in the baseline estimation. Both $\gamma_{+}$and $\gamma_{-}$are higher with $\gamma_{-}>\gamma_{+}$. Age squared has a strongly significant negative effect, while the time dummies no longer display a negative time trend. This suggests that the time trend in our baseline estimations is caused by the age effect.

In order to test for robustness of our results we also conducted estimations for the Galanter and Tversky and Kahneman (GTK) specification of the impact of relative income in equation (4) (see Sec. 4.3), for three alternative populations, and with random individual effects. The estimates for the GTK specification are shown in the third column of Table 2. The relative-income coefficients $\gamma_{+}=0.055$ and $\gamma_{-}=1.146$ are positive, and $\gamma_{-}$is significant, but $\gamma_{+}$is insignificant. The absolute-income coefficient $\beta$ is insignificant and the other coefficients are similar to those for equation (4). The exponents $\rho_{+}=0.568$ and $\rho_{-}=0.672$ indicate significant concavity of $S$ in negative as well as positive relative income. The degrees of these concavities do not significantly differ. Finally, loss aversion only holds for $\left|G_{-}\right|=G_{+}>0.029$, so for incomes more than $2.9 \%$ higher or lower than the reference income (note that by definition the slope $\partial R / \partial G_{-}$is zero at $G_{-}=0$; see Sec. 4.3). Thus, these results are more or less in line with those for our baseline estimations with some characteristics being more significant despite of the drawbacks of the GTK specification (as mentioned in Sec. 4.3). 
Equation (4) was also estimated for the subpopulations of West German men and women and for the sample from East Germany (see Sec. 5.2). For both West German men and women the relativeincome coefficients $\gamma_{+}$and $\gamma_{-}$are significantly positive with the coefficients for women being insignificantly higher. The absolute-income coefficient $\beta$ is insignificant for both sexes. Furthermore, for both men and women $S$ is insignificantly concave in positive relative income (according to a Wald test) and significantly concave in negative relative income with the concavity for men being insignificantly stronger. Thus, there is no significant difference in the effects of relative income between the sexes. For the East-German sample we found significantly positive relative-income coefficients $\gamma_{+}$and $\gamma_{-}$, which are insignificantly higher than the estimates for West Germany in Table 2. The effect of absolute income is again insignificant and $S$ is concave in positive as well as negative relative income, but both concavities are insignificant. This last result may be related to the smaller sample size for Eastern Germany (36313 observations).

Finally, Equation (4) was estimated with random instead of fixed individual effects (along the lines of Ferrer-i-Carbonell, 2005). In this case the exponents $\rho_{+}$and $\rho_{-}$could not be estimated directly, but only via an estimation of equation (4) for a grid of fixed values of $\rho_{+}$and $\rho_{-}$and determination of the global maximum of the log likelihoods (cf. Appendix A). The results were similar to those for the fixed individual effects in Table 2 with a somewhat higher coefficient $\gamma_{-}$and a somewhat lower coefficient $\gamma_{+}$, but the differences are not significant. Hence, we did not find indications of significant differences between long-run level and short-run shock effects of relative income (see Sec. 5.2). On the other hand, we found a strongly significant positive effect of the mean of In real income over the sample period. Although this effect is supposed to account for possible correlations of unobservable individual characteristics like optimism and intelligence with absolute income, a part of the effect may be due to long-run level effects of absolute income being higher than short-run shock effects. ${ }^{16}$ It can then not be concluded that long-run level effects of absolute income are insignificant and significantly lower than long-run level effects of relative income (hypothesis H3).

\section{Possible explanations and behavioural implications}

\subsection{Explanations}

From the perspective of prospect theory, the most striking result that we found is that of strongly rising sensitivity of life satisfaction $S$ to more negative values of relative income. On the basis of prospect theory we expected the opposite, namely a diminishing sensitivity of $S$ to more negative relative

\footnotetext{
${ }^{16}$ It is remarkable that Ferrer-i-Carbonell (2005) and Ferrer-i-Carbonell and Frijters (2004) interpret the effect of mean $\ln$ income solely as a correction for correlation of the random individual effect with income, whereas Van Praag et al. (2003) and Van Praag and Ferrer-i-Carbonell (2004) consider it as evidence for long-run effects of income being higher than short-run shock effects. In our view, a combination of both interpretations is the most correct one.
} 
income. Although our result is in line with the standard assumption of diminishing marginal utility of income in microeconomics, the contradiction with prospect theory calls for an explanation. One possible explanation is that the average income in the reference group of a person affects her (his) life satisfaction not only since she compares her income with this reference income, but also since her income relative to the reference income affects the extent to which she and her family can participate in social activities in the reference group. Such social activities, like trips, theatre visits, school outings, etc. cost money, and tend to be more costly as the average income in the reference group is higher. When your income is only little below the reference income, this will not be a problem, but if your income is considerably lower, it may become a financial problem for you and your family to participate in all social activities that your family members would like to participate in. As your income falls increasingly short of that in your reference group, it becomes increasingly and more than proportionally hard to raise the funds to participate in the social activities of the reference group.

In general, there seem to be two channels through which relative income affects life satisfaction. First, a direct, subjective perception effect of social comparison, which, according to the prospect theory, leads to a diminishing marginal sensitivity of life satisfaction to more positive as well more negative levels of relative income. Second, an indirect, objective functioning (Sen, 1985) effect of a lack of social participation, leading to a diminishing marginal sensitivity of life satisfaction to more positive relative income, but to a rising marginal sensitivity of life satisfaction to more negative relative income (see Vendrik and Hirata, 2003, for the distinction between both kinds of effect). In the context of prospect theory the latter effect may also be interpreted as a social version of the ruin effect for high losses as postulated by Kahneman (2003, p. 705). In the positive domain the diminishing marginal sensitivities of life satisfaction to relative income due to social comparison and social participation effects reinforce each other, whereas in the negative domain the diminishing marginal sensitivity of life satisfaction to relative income due to social comparison is counteracted and even dominated by the rising marginal sensitivity of life satisfaction to relative income due to social participation deficits. This interpretation is supported by our result from a likelihood-ratio test that reported life satisfaction $R$ is significantly more concave in positive relative income than it is in negative relative income. Since variations in $R$ around a specific social reference income cover only a small range of the total scale of $R$, and hence are relatively insensitive to distortions of this scale (see Sec. 7.1), this result probably carries over to true life satisfaction $S$.

Thus, in the present case the objective functioning effect of a lack of social participation seems to be more important for life satisfaction than the subjective perception effect of social comparison. In terms of the ruin effect in prospect theory, we may then say that in our case a social version of the ruin effect dominates the social comparison effect already for small losses. However, other interpretations of our results are also possible. An interesting one is that people whose income is below their 
reference income may cope with this by choosing a new social reference group with a lower average income. Prospect theory then predicts that life satisfaction will be concave in income higher than this new reference income, which however is lower than the reference income used in the estimations. Even if prospect theory is right in predicting that life satisfaction is convex in income lower than the new reference income, the estimations with the overrated reference income can then still result in an, on average, concave shape of life satisfaction in income below this overrated reference income (Huffman, personal communication). On the other hand, the finding that people are significantly less satisfied below their overrated reference income then remains. This might be due to the new reference group consisting of people with a lower educational level, among which the person feels less at home.

\subsection{Implications for behaviour}

The properties of the relative-income dependence of life satisfaction that have been discussed above may also have implications for certain decisions that people take. In general, people can be expected to aim at raising their life satisfaction by their decisions. By now there is a lot of evidence that people are often not successful in that, for instance when they fail to take into account that when their own income rises that of others may rise as well (implying little change in their relative income, and hence in their life satisfaction, see Sec. 6.1). However, this lack of anticipation of changes in exogenous variables does not deny that the structure of their decision utility function may be similar to that of their experienced utility function of life satisfaction (cf. Stutzer, 2003). In such a situation, the concavity properties of the latter function that we have found have interesting implications.

First, when the decision involves risky alternatives, the decision-taker will be risk averse for negative as well as positive relative income. This is in contrast to the risk seeking in losses that is implied by prospect theory. The concavity of life satisfaction in relative income may be said to cause this risk aversion by implying 'elementary' loss aversion relative to any specific positive/negative level of relative income (see Sec. 4.2.). An appealing feature of the power-function specification in equation (4) is that it can easily be shown to imply increasing relative risk aversion relative to the reference income ${ }^{17}$ for rising positive relative income as well as for falling negative relative income. In the positive domain this seems to be consistent with what many empirical studies find (Köbberling et al, 2004).

Second, in a context of riskless labour supply decisions, when the income is the result of a choice of working hours of effort, there are two implications. The first one is an application of a model for status behaviour that has been developed by Clark and Oswald (1998). Translated in the context of

\footnotetext{
${ }^{17}$ Note that the constant measures of relative risk aversions $\rho_{ \pm}$of the power function in (4) hold with respect to $Y / Y_{r}=0$.
} 
our life-satisfaction study, that model addresses the question whether people will raise or lower their working hours or effort when their social reference income $Y_{r}$ rises. According to the so-called ratiocomparison variant of the model, the strong concavity of $S$ in positive relative income that is associated with $\rho_{+}=1.93>1$ implies that in the positive domain people will raise their working hours or effort when $Y_{r}$ rises (following behaviour in the terminology of Clark and Oswald). On the other hand, the weaker concavity of $S$ in negative relative income that is associated with $\rho_{-}=0.79<1$ implies that in the negative domain people will start to work less or make less effort when $Y_{r}$ rises (deviant behaviour). Unfortunately, both implications are insignificant since neither $\rho_{+}$nor $\rho_{-}$differ significantly from one according to both a t-test and a likelihood-ratio test. In other words, for positive as well as negative income the estimated power-function specification in equation (4) does not significantly differ from a logarithmic one, according to which people do not react to a rise in their reference income.

Another labour supply implication is suggested by research of Goette et al. (2004) on withinday labour supply of cabdrivers and bicycle messengers. They formulate an intertemporal model of reference-dependent preferences for allocation of effort over a working day. The model is based on the Kahneman-Tversky value function with an income target acting as the reference point. The convexity of the value function for income below this target and the concavity for income above the target lead to the prediction that in the course of the day effort will first increase as earnings approach the target and then decrease as earnings have passed the target. This pattern is confirmed by empirical studies of the labour supply of cabdrivers and bicycle messengers. However, the estimates obtained for our life satisfaction function suggest a different pattern: when the social reference income acts as an income target, the concavity of the life satisfaction function for negative as well as positive relative income implies diminishing marginal life satisfaction as income rises. This would imply falling effort or working hours as income rises for levels below as well as above the target. A possible explanation for this difference in effort pattern is that in the behaviour of cabdrivers and bicycle messengers clearly a subjective perception effect of comparison with the income target is the main effect, whereas in the present life satisfaction context an objective deprivation effect of lack of social participation seems to dominate.

\section{Conclusion}

This paper investigated seven hypotheses about the impact of social reference income on individual life satisfaction. These hypotheses are based on Kahneman and Tversky's prospect theory, which uses an asymmetric value function to explain human decisions. This paper seems to be the first to test the characteristics of this value function for experienced utility. The estimation results confirm 
asymmetric effects for positive and negative relative income, and indicate concavity of life satisfaction in positive relative income. But in contrast to prospect theory, life satisfaction turns out to be significantly concave in negative relative income as well. Moreover, under plausible assumptions on the cardinal properties of the 'true-life-satisfaction' scale, this result is shown to be robust to extreme distortions of the reported-life-satisfaction scale. The result is not as surprising as it may seem from the perspective of prospect theory. People participate in activities within their social reference groups. As their income is lower it becomes more and more difficult to do so because they don't have enough money for these activities. It is, therefore, quite understandable that the marginal effect of a fall in income below the reference income increases with the relative income gap.

\section{Appendix A. Non-linear estimation of $\rho_{+}$and $\rho_{-}$and likelihood-ratio tests}

The non-linear estimation procedure for equation (4) required starting values of $\rho_{+}$and $\rho_{-}$close to their final values due to the closeness of these values to 0 (causing overflow). To obtain suitable starting values of $\rho_{+}$and $\rho_{-}$, we first estimated equation (4) for a grid of fixed values of $\rho_{+}$and $\rho_{-}$ between -4 and 4 with a difference 0.1 between successive values. The log likelihoods for all these fixed values of $\rho_{+}$and $\rho_{-}$revealed a lower and very flat local maximum besides the sharper absolute maximum for both $\rho_{+}$and $\rho_{-}$. For $\rho_{-}$this did not pose a problem because the local maximum is located at about $\rho_{-}=4$, i.e far above 0 . Applying a likelihood-ratio test to the null-hypothesis $\mathrm{H}_{0}$ : $\rho_{-}=0.0$ yielded $2|\ln L(0.785)-\ln L(0.0)|=11.34>3.86\left(\chi^{2}(1)\right.$ threshold value at $\left.\mathrm{p}=.05\right)$, and so rejection of $\mathrm{H}_{0}$. Thus, just as with the t-test (or, equivalently, Wald test), we can conclude that $\rho_{-}=0.785$ is significantly positive. For $\rho_{+}$matters are more complicated since the local maximum is now located at $\rho_{+}=-1.0$, i.e. below 0 . This seems to explain the large standard error in the estimate 1.928 for $\rho_{+}$. However, applying a likelihood-ratio test to the null-hypothesis $\mathrm{H}_{0}: \rho_{+}=-1.0$ (i.e. at the local-maximum) yielded $2|\ln L(1.928)-\ln L(-1.0)|=11.64>3.86$, and so rejection of $\mathrm{H}_{0}$. Since $\ln L\left(\rho_{+}\right)$is lower than the local maximum $\ln L(-1.0)$ for any other non-positive value of $\rho_{+}$, it then follows that a likelihood-ratio test rejects the null-hypothesis $\mathrm{H}_{0}: \rho_{+}=\rho_{+0}$ for any $\rho_{+0} \leq 0$.

\section{Appendix B. Derivation of convexity parameter $r$ and likelihood-ratio tests for condition (5)}

The three restrictions $\hat{R}(5)=5, \hat{R}(7)=7$ and $\hat{R}(10)=9$ on $\hat{R}(S)=a(S-c)^{1-b}$ in Section 7.1 correspond to the restrictions $S(5)=5, S(7)=7$ and $S(9)=10$ on the inverse function $S(\hat{R})=\hat{R}^{1+r} / a^{1+r}+c$. Substituting the latter three restrictions into the latter function yield the equations $5^{r^{\prime}} / a^{r^{\prime}}+c=5, \quad 7^{r^{\prime}} / a^{r^{\prime}}+c=7,9^{r^{\prime}} / a^{r^{\prime}}+c=10$, where $r^{\prime}=1+r$. Subtracting the first equation from the second yields $7^{r^{\prime}}-5^{r^{\prime}}=2 a^{r^{\prime}}$ and subtracting the second equation from the third yields $9^{r^{\prime}}-7^{r^{\prime}}=3 a^{r^{\prime}}$. Dividing the latter equation by the former and rewriting leads to the equation 
$9^{r^{\prime}}-2.5 * 7^{r^{\prime}}+1.5 * 5^{r^{\prime}}=0$. Solving this equation numerically yields $r^{\prime}=2.41$, and so $r=1.41$. The other sets of restrictions yield in an analogous way $r=5.30$ and $r=2.58$, respectively.

Besides Wald tests, we also did likelihood-ratio tests to determine whether condition (5) is satisfied significantly for positive relative income. The $\mathrm{H}_{0}$ of equality: $5 \rho_{+}=\gamma_{+} r$ implies $\rho_{+}=0.0586 r$. First, consider the highest $r=5.30$ for the implausibly extreme distortion. The corresponding $\rho_{+}$equals 0.31 . Hence, for $\rho_{+}=0.40$ (for which we obtained a log-likelihood value, see App. A) condition (5) is just fulfilled. Applying a likelihood-ratio test to $\mathrm{H}_{0}: \rho^{+}=0.40$ yields $2|\ln L(1.93)-\ln L(0.40)|=10.68>3.86$, and so rejection of $\mathrm{H}_{0}$. This means that the estimated $\rho_{+}=1.928$ is significantly higher than $\rho_{+}=0.40$, for which condition (5) is satisfied. We can then conclude that, according to a likelihood-ratio test for $r=6.30$, concavity condition (5) is satisfied significantly for our estimated $\rho_{+}=1.928$. Hence, even for this implausibly extreme distortion of the reported-life-satisfaction scale concavity condition (5) is fulfilled significantly. It then immediately follows that concavity condition (5) is also fulfilled significantly for the lower $r=1.41$ and $r=2.58$. Thus, in all cases we have a contradiction with the result from a Wald test.

\section{References}

Blanchflower, D.G. and A.J. Oswald (2004). "Well-being over Time in Britain and the USA". Journal of Public Economics, 88, 1359-1386.

Clark A.E. and A.J. Oswald (1998), "Comparison-Concave Utility and Following Behaviour in Social and Economic Settings", Journal of Public Economics, 70, 133-155.

Diener, E., E. Sandvik, L. Seidlitz, and M. Diener (1993). "The Relationship between Income and Subjective Well-Being: Relative or Absolute?" Social Indicators Research, 28, 195-223.

Duesenberry, J.S. (1949), Income, Saving and the Theory of Consumer Behavior, Cambridge, MA.

Easterlin, R.A. (1974). "Does Economic Growth Improve the Human Lot? Some Empirical Evidence.” In P. A. David and M. W. Reder (eds.), Nations and Households in Economic Growth: Essays in Honor of Moses Abramowitz. New York and London: Academic Press: 89-125.

Easterlin, R.A. (1995), "Will Raising the Incomes of All Increase the Happiness of All?", Journal of Economic Behavior and Organization, 27, 35-47.

Easterlin, R.A. (2001). "Income and Happiness: Towards a Unified Theory". The Economic Journal, 111 (473), 465-484

Ferrer-i-Carbonell, A. (2005). "Income and Well-being: An Empirical Analysis of the Comparison Income Effect", Journal of Public Economics, 89, 997-1019.

Ferrer-i-Carbonell, A. and P. Frijters (2004). "How Important is Methodology for the Estimates of the Determinants of Happiness?". The Economic Journal, 114 (July), 641-659.

Festinger, L. (1954). “A Theory of Social Comparison.” Human Relations, 7, 117-140. 
Frank, R.H. (1997). “The Frame of Reference as a Public Good”, The Economic Journal, 107 (Nov), 1832-47.

Frey, B.S., and A. Stutzer (2002a). Happiness and Economics: How the Economy and Institutions Affect Well-Being. Oxford: Princeton University Press.

Frey, B.S. and A. Stutzer (2002b). "What can economists learn from happiness research?", Journal of Economic Literature, 40: 402-435.

Galanter, E. (1990). "Utility Functions for Nonmonetary Events”, American Journal of Psychology, 103 (4), 449-470.

Glatzer, W. (1991). "Quality of life in advanced industrialized countries: The case of West Germany", in F. Strack, M. Argyle and N. Schwarz (eds.), Subjective Well-Being: An Interdisciplinary Perspective. Oxford: Pergamon: 261-279.

Goette, L., E. Fehr, and D. Huffman (2004), "Loss Aversion and Labor Supply", Journal of the European Economic Association, 2 (2-3), 216-218.

Johansson-Stenman, O. and P. Martinsson (2005), "Identity, Self-Deception and Subjective WellBeing", Working paper, Department of Economics, Götenborg University.

Kahneman, D. (1999), "Objective Happiness", in D. Kahneman, E. Diener, and N. Schwarz (eds.), Well-Being: The Foundations of Hedonic Psychology, New York: Russell Sage Foundation, Ch. 1.

Kahneman, D. (2003), “A Perspective on Judgment and Choice: Mapping Bounded Rationality", American Psychologist, 58, 697-720.

Kahneman, D., E. Diener, and N. Schwarz (1999), Well-Being: The Foundations of Hedonic Psychology, New York: Russell Sage Foundation.

Kahneman, D., J.L. Knetch, and R.H. Thaler (1991), "Anomalies: The Endowment Effect, Loss Aversion, and Status Quo Bias", Journal of Economic Perspectives, 5, 1: 193-206.

Kahneman, D. and A. Tversky (1979), "Prospect Theory: An Analysis of Decision under Risk", Econommetrica, 47, 263-291.

Kahneman, D., P.P. Wakker and R. Sarin (1997), "Back to Bentham?: Explorations of Experienced Utility", The Quarterly Journal of Economics, May, 375-405.

Kapteyn, A., and T. Wansbeek: 1985, "The individual welfare function: A review". Journal of Economic Psychology, 6, 333-363.

Köbberling, V., C. Schwieren and P.P. Wakker (2004), "Prospect-Theory's Diminishing Sensitivity versus Economic's Intrinsic Utility of Money: How the Introduction of the Euro Can Be Used to Disentangle the Two Empirically", Working paper, Faculty of Economics and Business Administration, Maastricht University.

Köbberling, V., and P.P. Wakker (2005), “An Index of Loss Aversion”, Journal of Economic Theory, 122: 119-131. 
Kroh, M., and M. Spiess (2005). "Documentation of Sample Sizes and Panel Attrition in the German Socio Economic Panel (SOEP), 1984-2004”, Data Documentation 6, 2005, DIW, Berlin.

Luttmer, E. (2004), "Neighbors as Negatives: Relative Earnings and Well-Being", NBER Working Paper 10667, National Bureau of Economic Research, Cambridge MA.

McBride, M. (2001). "Relative-Income Effects on Subjective Well-Being in the Cross-section", Journal of Economic Behavior and Organization, 45, 251-278.

Oswald, A.J. (2005). "On the Common Claim that Happiness Equations Demonstrate Diminishing Marginal Utility of Income”. IZA Discussion Paper, No. 1781, IZA, Bonn.

Schyns, P. (2002). "Wealth Of Nations, Individual Income and Life Satisfaction in 42 Countries: A Multilevel Approach." Social Indicators Research, 60, 5-40.

Sen, A. K. (1985). Commodities and Capabilities. Amsterdam: North-Holland.

Senik, C. (2004), "When Information Dominates Comparison: Learning from Russian Subjective Panel Data', Journal of Public Economics, 88, 2099-2123.

Stutzer, A. (2004), "The Role of Income Aspirations in Individual Happiness, Journal of Economic Behavior and Organization, 54, 89-109.

Stutzer, A. (2003), "Income Aspirations, Subjective Well-Being and Labor Supply", Working paper, Institute for Empirical Research in Economics, University of Zurich.

Swalm, R.O. (1966), “Utility Theory: Insights into Risk Taking”, Harvard Business Review, 44, 123136.

Tversky, A. and D. Kahneman (1991), "Loss Aversion in Riskless Choice: A Reference-Dependent Model", The Quarterly Journal of Economics, 106, 1039-1061.

Tversky, A. and D. Kahneman (1992), "Advances in Prospect Theory: Cumulative Representation of Uncertainty", Journal of Risk and Uncertainty, 5, 297-323.

Van Praag, B.M.S. and A. Ferrer-i-Carbonell (2004), Happiness Quantified: A Satisfaction Calculus Approach, Oxford University Press.

Van Praag, B.M.S., P. Frijters, A. Ferrer-i-Carbonell (2003), "The Anatomy of Subjective WellBeing”, Journal of Economic Behavior \& Organization, 51, 29-49.

Vendrik, M. and J. Hirata (2003), "Experienced versus Decision Utility of Income: Relative or Absolute Happiness", Research Memorandum METEOR, RM/03/039, Faculty of Economics and Business Administration, Maastricht University, forthcoming in L. Bruni and P.L. Porta (eds.; 2006), Handbook of Economics and Happiness, Edward Elgar

Wagner, G.G., R.V. Burkhauser, and F. Behringer (1993), "The English Language Public Use File of the German Socio-Economic Panel, Journal of Human Resources, 28: 429-433.

Wakker, P.P. and A. Tversky (1993), "An axiomatization of cumulative prospect theory”, Journal of Risk and Uncertainty, 7: 147-176. 
Winkelmann, L. and R. Winkelmann (1998), "Why are the Unemployed So Unhappy? Evidence from

Panel Data”. Economica, 65, 1-15.

Table 1. Estimation results for testing hypotheses 1-3 and 7

Linear least-squares estimation with fixed individual and time effects for Western Germany 1984-2001, with White cross-section standard errors

Equation 1

Equation 2

Equation 2, asymmetric

\begin{tabular}{lcccccc}
\hline Variable & Coefficient & T-ratio & Coefficient & T-ratio & Coefficient & T-ratio \\
\hline Constant & 2.158 & 2.05 & 2.158 & 2.05 & 2.156 & 2.06 \\
Ln(family income) & 0.313 & 14.04 & 0.003 & 0.04 & 0.010 & 0.12 \\
Ln(reference income) & -0.310 & -4.02 & & & & \\
Ln(fam. inc./ref. inc.) & & & 0.310 & 4.02 & & \\
Pos. ln (fam. inc./ref. inc.) & & & & & 0.207 & 2.34 \\
Neg. ln (fam. inc./ref. inc.) & & & & & 0.358 & 4.78 \\
Ln(number of adults) & -0.141 & -6.02 & -0.141 & -6.02 & -0.141 & -6.02 \\
Ln(1+number of children) & -0.076 & -2.27 & -0.076 & -2.27 & -0.079 & -2.35 \\
Unemployed & -0.633 & -11.96 & -0.633 & -11.96 & -0.627 & -11.82 \\
Ln(years of education) & -0.020 & -0.18 & -0.020 & -0.18 & -0.022 & -0.19 \\
Ln(age) & 1.271 & 9.59 & 1.271 & 9.59 & 1.267 & 9.53 \\
Couple & 0.305 & 10.08 & 0.305 & 10.08 & 0.292 & 9.97 \\
Single parent & -0.168 & -4.69 & -0.168 & -4.69 & -0.174 & -4.87 \\
Couple with children below 17 & -0.188 & -8.14 & -0.188 & -8.14 & -0.183 & -8.00 \\
Couple with children above 16 & -0.115 & -3.87 & -0.115 & -3.87 & -0.114 & -3.88 \\
Couple with children both & & & & & & \\
below 17 and above 16 & 0.160 & 3.80 & 0.160 & 3.80 & 0.148 & 3.57 \\
Ln(1+weekly hours worked) & 0.021 & 1.00 & 0.019 & 0.93 & 0.018 & 0.89 \\
Weekly hours dummy & 0.043 & 0.66 & 0.041 & 0.63 & 0.040 & 0.61 \\
& & & & & & 102068 \\
Number of observations & 102068 & & 102068 & & 11077 & \\
Number of individuals & 11077 & & 11077 & & -171306.7 & \\
Log likelihood & -171313.8 & & -171313.8 & & 0.440 & \\
Adjusted R & 0.440 & & 0.440 & & &
\end{tabular}


Table 2. Estimation results for testing hypotheses 2, 4, 5 and 7

Nonlinear least-squares estimation with fixed individual and time effects for Western Germany 19842001, with White cross-section standard errors

\begin{tabular}{lcccccc} 
& \multicolumn{2}{c}{ Equation 3 } & \multicolumn{2}{c}{ Equation 4 } & \multicolumn{2}{c}{ GTK equation } \\
\hline Variable & Coefficient & T-ratio & Coefficient & T-ratio & Coefficient & T-ratio \\
\hline Constant & 2.205 & 2.09 & 2.139 & 2.03 & 1.604 & 1.79 \\
Ln(family income) & -0.003 & -0.03 & 0.015 & 0.17 & 0.096 & 1.62 \\
Rel. income term & 0.308 & 3.50 & & & & \\
$\rho$ & 1.095 & 7.37 & & & & \\
Pos. rel. income term & & & 0.293 & 3.88 & 0.055 & 1.15 \\
$\rho_{+}$ & & & 1.928 & 1.58 & 0.568 & 3.34 \\
Neg. rel. income term & & & 0.404 & 3.21 & 1.146 & 2.25 \\
$\rho_{-}$ & & & 0.785 & 4.24 & 0.672 & 2.55 \\
Ln(number of adults) & -0.139 & -6.13 & -0.149 & -6.44 & -0.150 & -6.2 \\
Ln(1+number of children) & -0.076 & -2.27 & -0.082 & -2.46 & -0.083 & -2.4 \\
Unemployed & -0.631 & -11.81 & -0.627 & -11.84 & -0.626 & -11.9 \\
Ln(years of education) & -0.021 & -0.18 & -0.018 & -0.16 & -0.024 & -0.21 \\
Ln(age) & 1.274 & 9.66 & 1.260 & 9.44 & 1.243 & 9.68 \\
Couple & 0.302 & 10.30 & 0.291 & 9.77 & 0.289 & 9.80 \\
Single parent & -0.170 & -4.79 & -0.172 & -4.83 & -0.175 & -4.83 \\
Couple with children below & & & & & & \\
17 & -0.187 & -8.06 & -0.183 & -8.17 & -0.183 & -8.26 \\
Couple with children above & & & & & & \\
16 & -0.115 & -3.88 & -0.111 & -3.82 & -0.112 & -3.80 \\
Couple with children both & & & & & & \\
below 17 and above 16 & 0.157 & 3.81 & 0.148 & 3.53 & 0.144 & 3.55 \\
Ln(1+weekly hours worked) & 0.021 & 1.00 & 0.019 & 0.93 & 0.019 & 0.90 \\
Weekly hours dummy & 0.043 & 0.66 & 0.041 & 0.63 & 0.040 & 0.61 \\
& & & & & & \\
Number of observations & 102068 & & 102068 & & 102068 & \\
Number of individuals & 11077 & & 11077 & & -11077 & \\
Log likelihood & -171312.2 & & -171302.3 & & 0.440 & \\
Adjusted R ${ }^{2}$ & 0.440 & & 0.440 & & & \\
& & & & & &
\end{tabular}




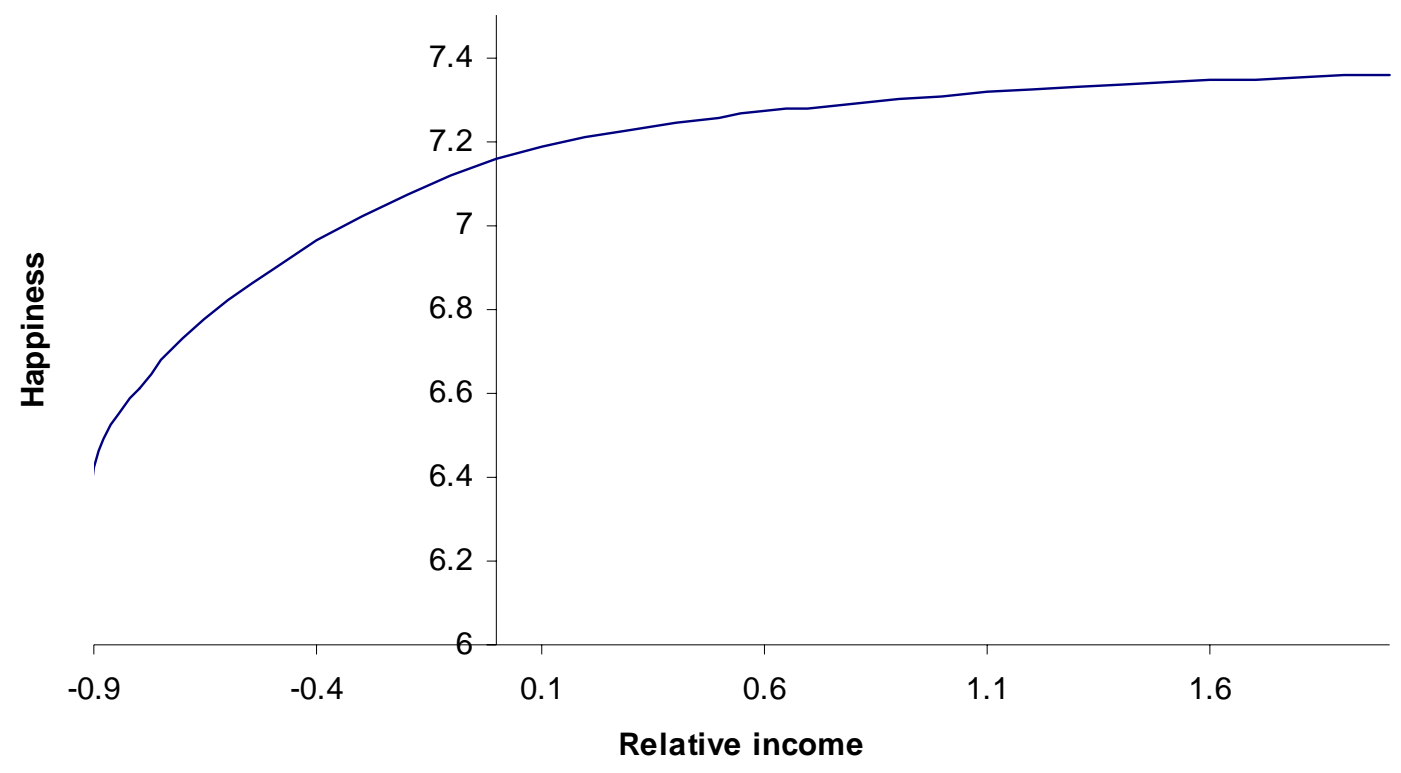

Figure 1. Dependence of individual life satisfaction on relative income for Western Germany, 1984-2001 (equation 4)

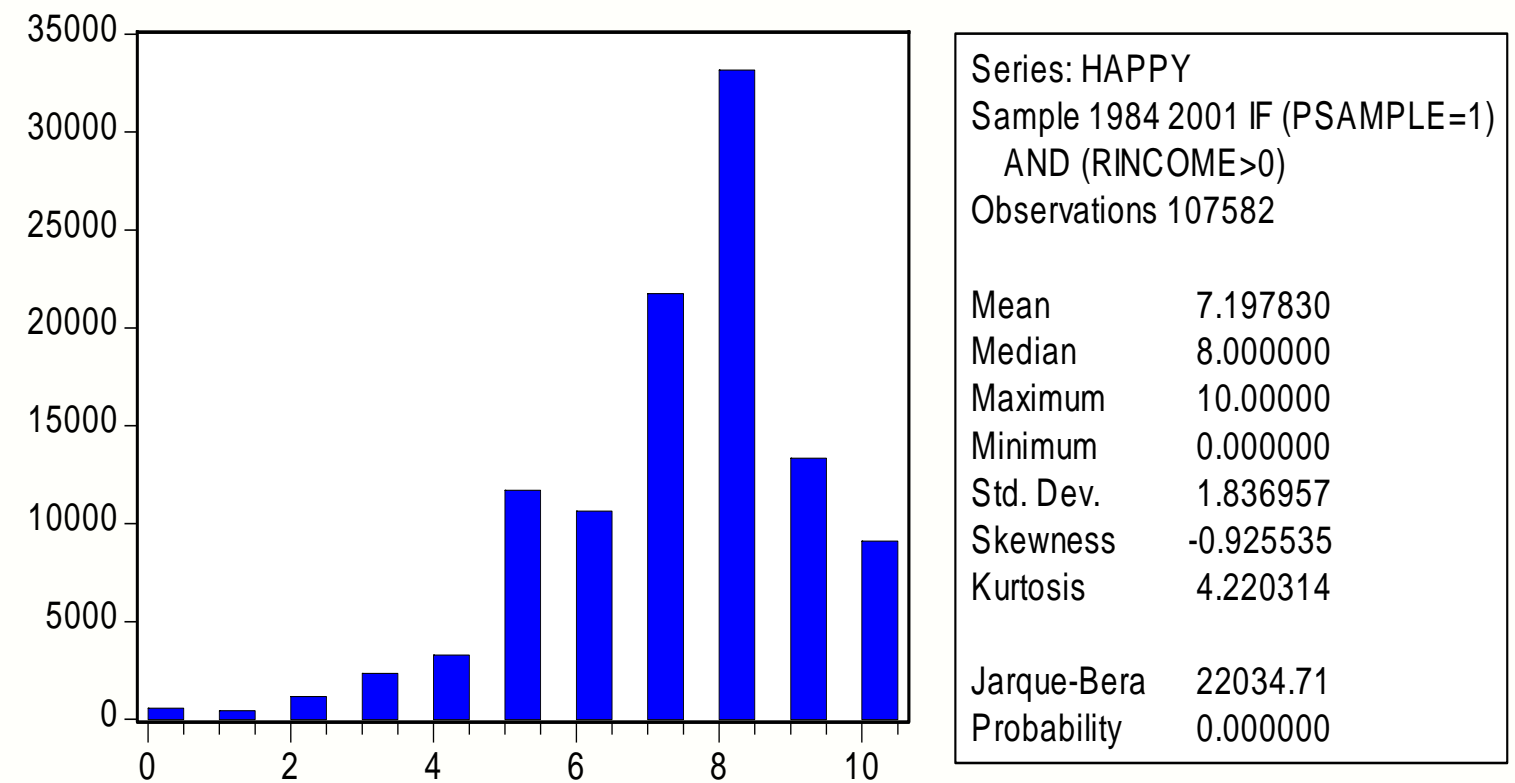

Figure 2. Sample distribution of reported life satisfaction for Western Germany, 19842001 